\title{
Effects of simvastatin on bleomycin-induced pulmonary fibrosis in female rats
} \author{
Suerdem, MD ${ }^{1}$ \\ ${ }^{1}$ Department of Pulmonary Medicine, Selcuklu Faculty of Medicine, Selcuk University, Konya-Turkey \\ 2 Department of Pulmonary Medicine, Istanbul Faculty of Medicine, Istanbul University, Istanbul-Turkey \\ 3 Department of Biochemistry, Selcuklu Faculty of Medicine, Selcuk University, Konya-Turkey \\ ${ }^{4}$ Department of Pathology, Meram Faculty of Medicine, Selcuk University, Konya-Turkey \\ ${ }^{5}$ Department of Pharmacology, Selcuklu Faculty of Medicine, Selcuk University, Konya-Turkey
}

Baykal Tulek, MD ${ }^{1 *}$; Esen Kiyan, MD²; Aysel Kiyici, MD³; Hatice Toy, MD; Hulagu Bariskaner, MD5; Mecit

\begin{abstract}
Statins reduce cholesterol levels by inhibiting 3-hydroxy-3-methylglutaryl coenzyme A reductase and have a major place in the treatment of atherosclerotic disease. Recent studies have shown anti-inflammatory properties of statins. The purpose of this study was to evaluate the anti-inflammatory effect of simvastatin on bleomycin (BLM)-induced pulmonary fibrosis in rats. A total of 31 female Sprague-Dawley rats were divided into four groups: (1) intratracheal (IT) phosphate-buffered saline (PBS) + intraperitoneal (IP) PBS (n=7); (2) IT BLM + IP PBS ( $\mathrm{n}=8)$; (3) IT BLM + low dose (LD) simvastatin ( $1 \mathrm{mg} / \mathrm{kg}$ daily, $\mathrm{n}=8)$; (4) IT BLM + high dose (HD) simvastatin (5 mg/kg daily, $\mathrm{n}=8)$. Simvastatin was administered IP for 15 days, beginning 1 day prior to IT BLM. The effect of simvastatin on pulmonary fibrosis was studied by measurements of IL-13, PDGF, IFN- $\gamma$, TGF- $\beta 1$ levels in bronchoalveolar lavage (BAL) fluid and lung tissue hydroxyproline (HPL) content and by histopathological examination (Ashcroft score). BLM caused significant change in BAL fluid cytokine levels and increased both HPL content and histopathological score ( $\mathrm{p}<0.001$ for all). While LD simvastatin had no effect on cytokine levels, HD significantly reduced IL-13 (15.12 $\pm 7.08 \mathrm{pg} / \mathrm{ml}$ vs. $4.43 \pm 2.34 \mathrm{pg} / \mathrm{mL} ; \mathrm{p}<0.05)$ and TGF- $\beta 1$ levels $(269.25 \pm 65.42 \mathrm{pg} / \mathrm{mL}$ vs. $131.75 \pm 32.65 \mathrm{pg} / \mathrm{mL} ; \mathrm{p}<0.05)$. Neither HD nor LD simvastatin attenuated HPL content or Ashcroft score. In conclusion, this study showed that LD simvastatin had no effect on a BLMinduced pulmonary fibrosis model, while the high dose caused partial improvement in profibrotic cytokine levels.
\end{abstract}

\section{INTRODUCTION}

Idiopathic pulmonary fibrosis (IPF) is a fatal disease of unknown origin. Its incidence is estimated to be 20 per 10,000 for males and 13 per 100,000 for females. The survival rate varies from 2 to 4 years (Kim et al., 2006). Patients with IPF are usually treated with corticosteroids and/or cytotoxic agents such as azathioprine or cyclophosphamide; the poor efficiency and significant side effects of these medications create, however, an urgent need for novel drugs with better efficacy and tolerance.

Statins are widely prescribed drugs with a positive effect on morbidity and mortality in cardiovascular disease. In recent years several studies have shown these positive effects of statins to be due both to their lipid lowering and antiinflammatory effect (Albert et al., 2001; Nissen et al., 2005; Ridker et al., 1998). Positive results in experimental trials have been obtained through the anti-inflammatory efficacy of statins in numerous respiratory disease models such as asthma, smoking-induced emphysema, pulmonary hypertension, IPF, acute lung injury and lung transplantation (Hothersall et al., 2006).

Bleomycin (BLM)-induced pulmonary fibrosis is the most common pulmonary experimental model in rodents (Chua et al., 2005). This model produces pathological findings similar to those in human pulmonary fibrosis; it is widely used in the assessment of potential antifibrotic drugs. A search of published literature shows that rodents used in studies carried out with BLM-induced pulmonary fibrosis model are male.
There is, on the other hand, a generally shared expectation that female animals may enhance fibrosis by increasing both inflammatory and immune responses through the estrogen hormones or a modified cytokine expression, although several studies indicate the opposite (Gharaee-Kermani et al., 2005; Voltz et al., 2008).

The aim of this study was to investigate the antiinflammatory and antifibrotic efficiency of simvastatin, the effectiveness of which was already shown in the BLM-induced pulmonary fibrosis model in doses approaching those used in humans.

\section{METHODS}

Animals

The study was approved by Selcuk University Experimental Medical Research and Application Center Experimental Animal Ethics Committee. Thirty-one female Sprague Dawley rats weighing $200-230 \mathrm{~g}$ were studied. The animals were maintained in a controlled environment and fed on rodent chow and tap water ad libitum, in 12-hour light, 12-hour dark cycles. They were free of respiratory and other diseases.

Preparation of simvastatin

Simvastatin (Merck, Sharp \& Dohme, Middlesex, U.K.) was prepared as a $4 \mathrm{mg} / \mathrm{mL}$ stock solution. Briefly, $4 \mathrm{mg}$ of simvastatin were dissolved in $100 \mu \mathrm{L}$ of ethanol and $150 \mu \mathrm{L}$ 
of $0.1 \mathrm{~N} \mathrm{NaOH}$ and incubated at $50{ }^{\circ} \mathrm{C}$ for $2 \mathrm{~h}$, then the $\mathrm{pH}$ was adjusted to 7 and the total volume corrected to $1 \mathrm{~mL}$. The stock solution was diluted to the appropriate concentration in sterile phosphate-buffered saline (PBS) immediately before use (McKay et al., 2004).

Experimental Model and Experimental Groups

All animals were anesthetized with a mixture of xylazine (10 mg/kg, Rompun; Bayer AG, Leverkusen, Germany) and ketamine (70 mg/kg, Ketalar ${ }^{\circledR}$; Parke Davis, Eczacibasi, Istanbul, Turkey) administered by intramuscular (IM) injection before the surgical procedures. The trachea was exposed after a small cervical skin incision and separation of strap muscles, and punctured with a 26-gauge needle for the administration of bleomycin sulphate (BLM; Bleocin-S, Nippon Kayaku Co., Ltd, Tokyo, Japan) (Borzone et al., 2001). A single dose of $2.5 \mathrm{U} / \mathrm{kg}$ BLM dissolved in $0.3 \mathrm{~mL}$ PBS was instilled by intratracheal (IT) injection. This dose of BLM was selected from previous experiments to cause consistent biochemical and histological damage without mortality (Serrano-Mollar et al., 2002). Control animals received $0.3 \mathrm{~mL}$ PBS IT.

Simvastatin solution was administered intraperitoneally (IP) in two different doses, low dose (LD, $1 \mathrm{mg} / \mathrm{kg}$ ) or high dose (HD, $5 \mathrm{mg} / \mathrm{kg}$ ) beginning 1 day before the start of BLM application. Control animals received PBS. The animals were randomly distributed into four weight-matched study groups: (1) IT PBS + IP PBS ( $n=7)$; (2) IT BLM + IP PBS ( $n=$ 8); (3) IT BLM + IP LD simvastatin ( $\mathrm{n}=8)$; (4) IT BLM + IP HD simvastatin $(\mathrm{n}=8)$.

The rats were sacrificed by transsection of the abdominal aorta while under an overdose of pentobarbital ( $80 \mathrm{mg} / \mathrm{kg}$ IP) 14 days after IT bleomycin or saline instillation.

\section{Bronchoalveolar lavage fluid}

After clamping the right main bronchus, bronchoalveolar lavage (BAL) fluid was obtained from the left lung. Lavage was performed four times with $3 \mathrm{~mL} \mathrm{NaCl} 0.9 \%$. Samples were stored in the refrigerator at $-80{ }^{\circ} \mathrm{C}$ until analysis. Levels of interleukin (IL)-13, interferon (IFN) $-\gamma$, platelet derived growth factor (PDGF)-A and transforming growth factor (TGF)- $\beta$ were performed with the ELISA technique using commercially available kits. The Invitrogen Rat IL-13 (BioSource, Invitrogen, USA,Cat \#KRC0132/KRC0131), Invitrogen Multispecies TGF- $\beta$ (BioSource, Invitrogen, USA,Cat \#KAC1688/KAC1688), Rat IFN- $\gamma$ (BenderMedSystems, Austria, Cat \#BMS621) and Quantikine Mouse/Rat PDGF-AB (R\&D Systems, USA, Cat \#MHD00) kits were used for determination of these parameters in BAL fluid.

Measurement of hydroxyproline concentration in the lung

The left lung was ligated and cut at the hilum, freed of extraneous tissue, blotted on filter paper and snap frozen in liquid nitrogen. The tissues were stored in Eppendorf tubes at $-80{ }^{\circ} \mathrm{C}$ until the time of biochemical analysis. Frozen tissue samples were weighed before analysis and subjected to alkaline hydrolysis. Briefly, the tissue samples were placed in Eppendorf tubes with $1 \mathrm{~mL}$ of $2 \mathrm{~N} \mathrm{NaOH}$; the tubes were sealed with rubber stoppers and incubated for one hour in an autoclave at $120{ }^{\circ} \mathrm{C}$. Derivatization followed hydrolysis and 50 $\mu \mathrm{L}$ of the sample was injected into an HPLC system (Shimadzu Prominence/Japan). A commercially available HPLC hydroxyproline (HPL) analysis kit (Eureka, Italy) was used for this analysis with a UV/VIS detector at $495 \mathrm{~nm}$. Lung tissue hydroxyproline contents were reported as $\mathrm{mg} / \mathrm{g}$ frozen tissue.

\section{Histological studies of the lungs}

Histopathological evaluation was carried out on the right lungs that were not lavaged. The right lung was fixed by IT infusion of formalin under $25 \mathrm{~cm}$ hydrostatic pressure. Lung tissue was embedded in paraffin and sections stained with hematoxylineosin for examination by light microscopy. Ashcroft's scoring system (Ashcroft et al., 1988) was used to estimate the severity of pulmonary fibrosis on a numerical scale in a blind evaluation by the same pathologist (HT) (Table 1).

\section{Stasistical Analysis}

We performed power analysis to determine the sample size. Effect size was based on results of the study of Ou et al. (2008), and sample size was set to 7 per group for a power of $80 \%$

\section{TABLE 1}

Characterization of the Ashcroft Scale

\begin{tabular}{ccc}
\hline Grade of fibrosis & Histological features \\
\hline 1 & Normal lung \\
2 & Minimal fibrous thickening of alveolar or bronchiolar vessels \\
3 & Increased fibrosis with definite damage to lung structure and formation of fibrous bands or small fibrous masses \\
4 & Severe distortion of structure and large fibrous areas; “honeycomb lung" is placed in this category \\
6 & Total fibrous obliteration of the field \\
7 &
\end{tabular}


and with a significance level of 0.05. Eight rats were included in groups receiving IT BLM considering probable animal loss during the study.

Descriptive results were expressed as mean \pm 1 standard deviation. Inferential statistical analysis was carried out by the Kruskal-Wallis variance analysis, with Dunn's multiple comparison test as a post hoc test. A p-value $<0.05$ was considered as statistically significant.

\section{RESULTS}

Effect of simvastatin on IL-13, PDGF, IFN- $\gamma$ and TGF- $\beta 1$ levels

BAL fluid recovery rate, ranging from 84 to $90 \%$, was not significantly different among the four groups. IT instillation of BLM caused significant increases in IL-13, PDGF, and TGF- $\beta 1$ and a significant decrease in IFN- $\gamma$ levels. HD simvastatin significantly decreased the levels of IL-13 and TGF- $\beta 1$ $(p<0.001)$. There was, however, no significant change in the PDGF or IFN- $\gamma$ levels. LD simvastatin administration did not correlate with any significant change in IL-13, PDGF, IFN- $\gamma$ or TGF- $\beta 1$ levels. Details are shown in Table 2.

Effect of simvastatin on HPL content

IT BLM caused a significant increase in lung HPL concentration, which is a marker of collagen deposition, on day $14(\mathrm{p}<0.001)$. Neither LD nor HD administration of simvastatin with IT BLM caused a significant decrease in HPL content (Table 3).

Histopathological assessment

Haematoxylin-eosin stained lung sections were examined by light microscopy on Day 14. The lungs of the control group animals showed normal, free alveoli and interalveolar spaces (Fig 1a). Those of animals given BLM presented inflammatory infiltration, alveolar wall thickening and increase in interstitial collagen deposition (Fig. 1b). The animals who had received pre-treatment with simvastatin before BLM showed moderate edema and inflammation of perialveolar tissues with increased fibrotic changes (Fig. 1c).

In the assessment of lung sections according to Ashcroft's scoring system, the BLM-PBS group had the highest Ashcroftfibrosis score. Either LD or HD simvastatin before IT BLM did not result in significant decrease in histopathological scores (Table 3).

\section{DISCUSSION}

In this study of the effect of simvastatin on BLM-induced pulmonary fibrosis in rats, we could not determine a positive effect of either a high $(5 \mathrm{mg} / \mathrm{kg})$ or a low $(1 \mathrm{mg} / \mathrm{kg})$ dose of simvastatin on fibrosis formation. Only the levels of IL-13 and TGF- $\beta 1$ were found to be lower in the simvastatin group than in the BLM group, at the dose of $5 \mathrm{mg} / \mathrm{kg}$.

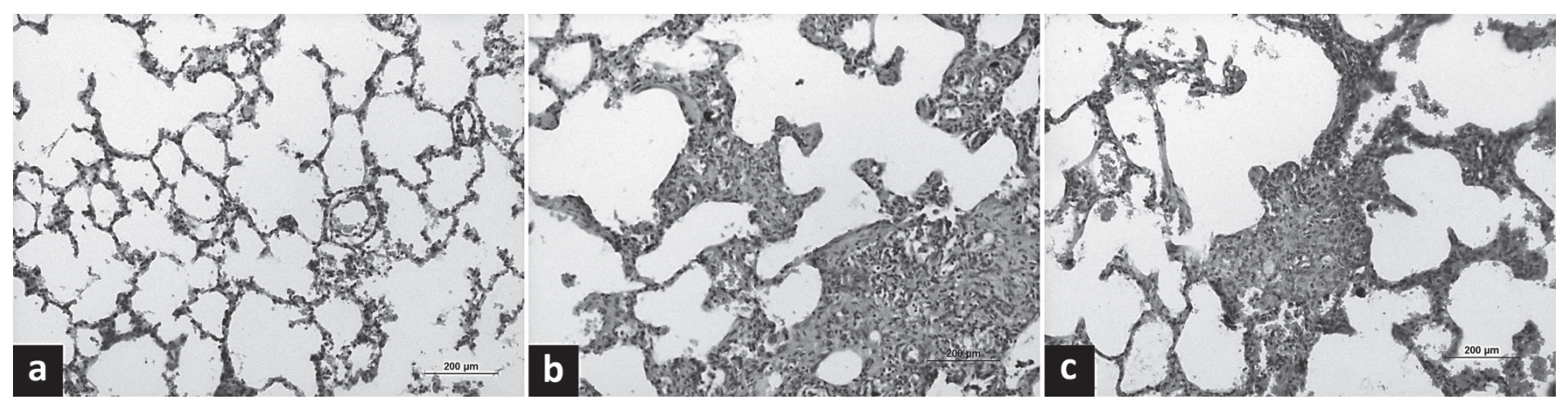

Figure 1: Histopathological examination of the anti-inflammatory and antifibrotic effects of simvastatin on bleomycin-instilled lungs. Lung sections stained with hematoxylin-eosin stain. (a): Normal lung tissues showing normal, open alveoli and interalveolar spaces with normal terminal bronchi (b): Bleomycin-treated lung sections showing severe congestion and edema of interalveolar space, inflammation, and thickened and collapsed alveoli with marked fibrosis. (c): High-dose simvastatin prior to bleomycin showing moderate inflammation, edema and fibrotic changes.

TABLE 2

Bronchoalveolar lavage (BAL) fluid levels of IL-13, PDGF-A, IFN- $\gamma$ and TGF- $\beta 1$ in control rats, rats given bleomycin only, and rats given either low-dose or high-dose simvastatin

\begin{tabular}{|c|c|c|c|c|}
\hline Groups & $\begin{array}{c}\text { IL-13 } \\
(\mathrm{pg} / \mathrm{ml})\end{array}$ & $\begin{array}{c}\text { PDGF-A } \\
(\mathrm{pg} / \mathrm{ml})\end{array}$ & $\begin{array}{c}\text { IFN- } \gamma \\
(\mathrm{pg} / \mathrm{ml})\end{array}$ & $\begin{array}{c}\text { TGF- } \beta 1 \\
(\mathrm{pg} / \mathrm{ml})\end{array}$ \\
\hline Control (IT PBS + IP PBS, n: 7) & $0.54 \pm 0.23$ & $15.48 \pm 1.57$ & $62.62 \pm 16.01$ & $24.42 \pm 4.27$ \\
\hline BLM+ IP PBS (n: 8) & $15.12 \pm 7.08^{*}$ & $58.70 \pm 15.11^{*}$ & $18.95 \pm 9.16^{*}$ & $269.25 \pm 65.42^{*}$ \\
\hline BLM+1 mg/kg simvastatin (n: 8) & $13.82 \pm 5.73$ & $54 \pm 8.80$ & $22.29 \pm 6.16$ & $231.75 \pm 68.31$ \\
\hline $\mathrm{BLM}+5 \mathrm{mg} / \mathrm{kg}$ simvastatin (n: 8) & $4.43 \pm 2.34^{* *}$ & $24.11 \pm 9.72$ & $34.79 \pm 8.79$ & $131.75 \pm 32.65^{* *}$ \\
\hline
\end{tabular}

IT: Intratracheal; IP: Intraperitoneal; PBS: Phosphate-buffered saline; BLM:Bleomycin; *: Compared to control group ( $<<0.001)$; **: Compared to BLM group ( $<<0.05$ ). 
TABLE 3

Hydroxyproline (HPL) contents and grade of pulmonary fibrosis in control rats, rats given bleomycin only, and rats given either low dose or high-dose simvastatin

\begin{tabular}{ccc}
\hline Groups & HPL (mg/g) & Ashcroft score \\
\hline Control (IT PBS + IP PBS; n: 7) & $0.36 \pm 0.06$ & $0 \pm 0$ \\
BLM+ IP PBS (n: 8) & $0.80 \pm 0.04^{*}$ & $3.12 \pm 1.35^{*}$ \\
BLM+1 mg/kg simvastatin (n: 8) & $0.76 \pm 0.05$ & $3 \pm 1.06$ \\
BLM+ 5 mg/kg simvastatin (n: 8) & $0.48 \pm 0.05$ & $1.5 \pm 0.53$ \\
\hline
\end{tabular}

IT: Intratracheal; IP: Intraperitoneal; PBS: Phosphate-buffered saline; BLM:Bleomycin;*: Compared to control group ( $p<0.001$ ). Ashcroft score; 0: Normal lung; 1: Minimal fibrous thickening of alveolar or bronchiolar vessels; 2-3: Moderate thickening of walls without obvious damage to lung architecture; 4-5: Increased fibrosis with definite damage to lung structure and formation of fibrous bands or small fibrous masses; 6-7: Severe distortion of structure and large fibrous areas; "honeycomb lung" is placed in this category; 8: Total fibrous obliteration of the field.

The anti-inflammatory effect of the statins is independent of their lipid reducing effect; different statins have different actions on inflammatory cells (Nagashima et al., 2006). Kiener et al. (2001) demonstrated that atorvastatin and simvastatin, the lipophilic statins, have a substantially greater antiinflammatory effect than hydrophilic pravastatin. It is therefore important to realize that all the statins cannot have the same potential. Some statins may even show effects opposite to those of others. For example, in a study with 27 healthy volunteers comparing the 14-day effects of simvastatin, $40 \mathrm{mg}$ and atorvastatin, $20 \mathrm{mg}$, simvastatin led to an increase in HLA-DR and MHC38 in T- cell expression, while the latter appeared to downregulate the same markers (Fehr et al., 2004). In addition, superantigen-mediated T-cell activation was inhibited by simvastatin, while atorvastatin, conversely, sensitized these cells. Simvastatin has been shown to be effective on the profibrogenic mechanisms in IPF and significantly inhibited the CTGF gene and protein expression, overriding induction by TGF $\beta-1$, a known potent inducer of CTGF (Watts et al., 2005). Several experimental trials showed an effect of simvastatin and pravastatin on BLM induced pulmonary fibrosis (Kim et al., 2010; Ou et al., 2008).

Experimental data suggest that the anti-inflammatory and antifibrotic effects of simvastatin could be utilized in clinical practice for pulmonary disease such as asthma and IPF. However, the positive experimental results could not be demonstrated in clinical trials. For example, in a study by Menzies et al. (2007) of the anti-inflammatory effect of simvastatin in asthma patients, simvastatin was not correlated with any significant changes in the inflammatory markers, lung volume or airway resistance. A retrospective review by Nadrous et al. (2004) of the contribution of ACE inhibitors and statins on IPF survival indicated that statins did not contribute to survival. Also, numerous case reports related to statin use in recent years have raised questions about the positive effects of statins in pulmonary fibrosis (Fernandez et al., 2008).

The effect of simvastatin on BLM-induced pulmonary fibrosis was previously discussed in one report only. In this study, Ou et al. (2008) evaluated the effect of simvastatin on histopathological scores, lung HPL content, inflammatory response, fibrogenic cytokines and profibrogenic markers. Administration of simvastatin for 28 days doses of 5 and $20 \mathrm{mg} / \mathrm{kg}$ showed statistically significant changes in all the parameters. The comparison of the antifibrotic activity of the high and low dose groups indicated a significant difference in favor of the high-dose group. In our study, on the other hand, simvastatin was administered at lower doses and for a shorter time; no significant change was seen in the pulmonary fibrosis markers.

New drugs are usually tested for safety and efficacy in animal models before being used in clinical trials. It is well known that discrepancies exist between animal and human data and that a drug that is active in the animal may be useless in the human (Perel et al., 2007). Such an occurrence is often due to inappropriate translation of the drug dose from one animal species to another. Dose calculation based on body surface area (BSA) is accepted as the most appropriate method for translating doses among species (Reagan-Shaw et al., 2008). A BSA-based translation of the doses used in our study would result in doses of approximately $12 \mathrm{mg}$ and $60 \mathrm{mg}$ daily doses for a human weighing $60 \mathrm{~kg}$. The dose range for simvastatin in human use is $20-80 \mathrm{mg} /$ day for cardiovascular disease; statinrelated side effects such as myopathy are known to be dosagedependent (Escobar et al., 2008). Furthermore, in experimental studies high doses of simvastatin are reported to increase the risk of toxicity and mortality (Palmer et al., 2004). In the study by Palmer et al. (2004) of statin effect in collagen-induced arthritis, the anti-inflammatory activity of simvastatin was seen only after administration of $40 \mathrm{mg} / \mathrm{kg}$; serious side effects were observed during treatment. Only 7 of 18 mice completed therapy.

Ou et al. (2008) sacrificed the rats after 28 days of IT BLM administration, while histological evaluation was performed after 14 days in our study. The time point of 14 days was considered as the most suitable for a comparative study in a BLM-induced PF model, as fibrosis is reported to decrease after 14 days (Izbicki et al., 2002). Also, in a study evaluating the immune modulating effects of statins (Fehr et al., 2004), a 14-day statin administration was shown to be sufficient for the immune system effects to occur. The selected 14-day evaluation period in our study appears to be optimal for judging both the simvastatin effect and the fibrosing effect of BLM.

TGF- $\beta 1$, PDGF-A, IL-13 and IFN- $\gamma$ are biochemical endpoints used in many fibrosis evaluations (Scotton and Chambers, 2007). We found an increase of TGF- $\beta 1$, PDGF-A and IL-13 levels, and a decrease in the IFN- $\gamma$ level, in line with the published literature. However, a significant decrease of IL-13 and TGF- $\beta 1$, compared to the BLM group, was only observed in the HD simvastatin group. TGF- $\beta$ is one of the principal mediators in the pathophysiology of pulmonary 
fibrosis. This cytokine affects extracellular matrix remodeling through multiple processes and is essential for several types of experimental fibrosis (Branton and Kopp, 1999). Therefore, inhibition of TGF- $\beta$ signaling was intensively studied to evaluate the efficiency of antifibrotic therapies. Positive effects on fibrosis of therapies targeting TGF- $\beta$ pathways were found (Bonniaud et al., 2005; de Gouville and Huet, 2006). Another profibrotic cytokine, IL-13, is a T-helper type 2 cytokine; it can stimulate the production of fibroblast collagen independently from TGF- $\beta$ (Kolodsick et al., 2004). The important role of IL-13 in pulmonary fibrosis was clearly shown both in in vivo and in vitro studies (Gharaee-Kermani et al., 2001; Zhu et al., 1999). Jakubzick et al. (2003) assessed the efficiency of a chimeric IL-13 immunotoxin (IL-13-PE) in BLM-challenged mice. This study showed that IL-13-binding cells are essential for BLM-induced PF and the importance of antifibrotic therapies targeting IL-13 in pulmonary fibrosis. Examining experimentally the effects of simvastatin on allergic airway reaction and airway reactivity, Zeki et al. (2009) showed that simvastatin decreases airway inflammation, inhibits T-cell type 1 and 2, and improves lung physiology in the asthmatic mouse model. Simvastatin was administered in a much higher dose $(40 \mathrm{mg} / \mathrm{kg})$ than in our study; the IL-13 level in the lung lavage fluid decreased significantly.

Most experimental PF studies hitherto reported have been carried out in male rats, since the female gender is defined as a crucial factor for the development and prognosis of IPF. However, there are controversial indications from studies, suggesting that both the male and the female gender play a negative role in pulmonary fibrosis. Gharaee-Kermani et al. (2005) investigated the effects of gender and estradiol on pulmonary fibrosis in female and male rats in the BLMinduced pulmonary fibrosis model. They found more frequent and severe fibrotic lesions in the female rats. In this study, BLM was administered at a dose of $7.5 \mathrm{U} / \mathrm{kg}$; all the male rats survived, while a high mortality rate of $80 \pm 5 \%$ was calculated for the female animals. Whereas Voltz et al. (2008), reported that androgens, too, play a worsening role in the BLM-induced pulmonary fibrosis model. However, invasive pulmonary function tests were used in this study and no significant difference could be shown between animals of either sex in terms of the results of frequently used biochemical and histological indices of pulmonary fibrosis. Opposite results have, however, been reported in some clinical studies. In humans, even though the IPF incidence is higher in men, the incidence of the familial form of IPF is higher in women, who also have a comparatively poorer prognosis (Barzo, 1985; Wockel and Sultz, 1995). Several studies have, to the contrary, reported a poorer the prognosis in men with IPF compared to women (Gribbin et al., 2006; Olson et al., 2007). In our study, histologically confirmed fibrosis was achieved in female rats with $2.5 \mathrm{U} / \mathrm{kg}$ BLM, without mortality. This finding is one of the important results of the study.

In conclusion, simvastatin could not be shown to exert a favorable effect on BLM-induced PF in our study in female rats. Partial favorable effects in biochemical targets, in the group given HD treatment, suggest that favorable results could be possible at such high doses when interpreted in combination with results from the other studies. However, considering the relationship between high-dose administration and the risk of toxicity, we believe that further studies should be conducted on this subject.

\section{REFERENCES}

ALBERT MA, DANIELSON E, RIFAI N, RIDKER PM (2001) Effect of statin therapy on C-reactive protein levels: the pravastatin inflammation/CRP evaluation (PRINCE): a randomized trial and cohort study. JAMA 286: 64-70.

ASHCROFT T, SIMPSON JM, TIMBRELL V (1988) Simple method of estimating severity of pulmonary fibrosis on a numerical scale. J Clin Pathol 41: 467-470.

BARZO P (1985) Familial idiopathic fibrosing alveolitis. Eur J Respir Dis 66: 350-352.

BONNIAUD P, MARGETTS PJ, KOLB M, SCHROEDER JA, KAPOUN AM, DAMM D, MURPHY A, CHAKRAVARTY S, DUGAR S, HIGGINS L, PROTTER AA, GAULDIE J, (2005) Progressive transforming growth factor beta1-induced lung fibrosis is blocked by an orally active ALK5 kinase inhibitor. Am J Respir Crit Care Med 171: 889-898.

BORZONE G, MORENO R, URREA R, MENESES M, OYARZÚN M, LISBOA C (2001) Bleomycin-induced chronic lung damage does not resemble human idiopathic pulmonary fibrosis. Am J Respir Crit Care Med 163: 1648-1653.

BRANTON MH, KOPP JB (1999) TGF-beta and fibrosis. Microbes Infect 1: 1349-1365.

CHUA F, GAULDIE J, LAURENT GJ (2005) Pulmonary fibrosis: searching for model answers. Am J Respir Cell Mol Biol 33: 9-13.

DEGOUVILLE AC, HUET S (2006) Inhibition of ALK5 as a new approach to treat liver fibrotic diseases. Drug News Perspect 19: 85-90.

ESCOBAR C, ECHARRI R, BARRIOS V (2008) Relative safety profiles of high dose statin regimens. Vasc Health Risk Manag 4: 525-533.

FEHR T, KAHLERT C, FIERZ W, JOLLER-JEMELKA HI, RIESEN WF, RICKLI H, WUTHRICH RP, AMMANN P (2004) Statin-induced immunomodulatory effects on human $\mathrm{T}$ cells in vivo. Atherosclerosis 175: 83-90.

FERNÁNDEZ AB, KARAS RH, ALSHEIKH-ALI AA, THOMPSON PD (2008) Statins and interstitial lung disease: a systematic review of the literature and of food and drug administration adverse event reports. Chest 134 : 824-830.

GHARAEE-KERMANI M, HATANO K, NOZAKI Y, PHAN SH (2005) Gender-based differences in bleomycin-induced pulmonary fibrosis. Am J Pathol 166: 1593-1606.

GHARAEE-KERMANI M, NOZAKI Y, HATANO K, PHAN SH (2001) Lung interleukin-4 gene expression in a murine model of bleomycin-induced pulmonary fibrosis. Cytokine 15: 138-147.

GRIBBIN J, HUBBARD RB, LE JEUNE I, SMITH CJ, WEST J, TATA LJ (2006) Incidence and mortality of idiopathic pulmonary fibrosis and sarcoidosis in the UK. Thorax 61: 980-985.

HOTHERSALL E, MCSHARRY C, THOMSON NC (2006) Potential therapeutic role for statins in respiratory disease. Thorax 61: 729-734.

IZBICKI, G., SEGEL, M.J., CHRISTENSEN, T.G., CONNER, M.W., BREUER, R., 2002, Time course of bleomycin-induced lung fibrosis. Int J Exp Pathol 83: 111-119.

JAKUBZICK C, CHOI ES, JOSHI BH, KEANE MP, KUNKEL SL, PURI RK, HOGABOAM, CM (2003) Therapeutic attenuation of pulmonary fibrosis via targeting of IL-4- and IL-13-responsive cells. J Immunol 171: 2684-2693.

KIENER PA, DAVIS PM, MURRAY JL, YOUSSEF S, RANKIN BM, KOWALA M (2001) Stimulation of inflammatory responses in vitro and in vivo by lipophilic HMG-CoA reductase inhibitors. Int Immunopharmacol 1: 105-118.

KIM DS, COLLARD HR, KING TE JR (2006) Classification and natural history of the idiopathic interstitial pneumonias. Proc Am Thorac Soc 3: 285-292.

KIM JW, RHEE CK, KIM TJ, KIM YH, LEE SH, YOON HK, KIM SC, LEE SY, KWON SS, KIM KH, KIM YK (2010) Effect of pravastatin on bleomycininduced acute lung injury and pulmonary fibrosis. Clin Exp Pharmacol Physiol 37: 1055-1063.

KOLODSICK JE, TOEWS GB, JAKUBZICK C, HOGABOAM C, MOORE TA, MCKENZIE A, WILKE CA, CHRISMAN CJ, MOORE BB (2004) Protection from fluorescein isothiocyanate-induced fibrosis in IL-13deficient, but not IL-4-deficient, mice results from impaired collagen synthesis by fibroblasts. J Immunol 172: 4068-4076.

MCKAY A, LEUNG BP, MCINNES IB, THOMSON NC, LIEW FY (2004) A novel anti-inflammatory role of simvastatin in a murine model of allergic asthma. J Immunol 172: 2903-2908.

MENZIES D, NAIR A, MELDRUM KT, FLEMING D, BARNES M, LIPWORTH BJ (2007) Simvastatin does not exhibit therapeutic antiinflammatory effects in asthma. J Allergy Clin Immunol 119: 328-335. 
NADROUS HF, RYU JH, DOUGLAS WW, DECKER PA, OLSON EJ (2004) Impact of angiotensin-converting enzyme inhibitors and statins on survival in idiopathic pulmonary fibrosis. Chest 126: 438-446.

NAGASHIMA T, OKAZAKI H, YUDOH K, MATSUNO H, MINOTA S (2006) Apoptosis of rheumatoid synovial cells by statins through the blocking of protein geranylgeranylation: a potential therapeutic approach to rheumatoid arthritis. Arthritis Rheum 54: 579-586.

NISSEN SE, TUZCU EM, SCHOENHAGEN P, CROWE T, SASIELA WJ, TSAI J, ORAZEM J, MAGORIEN RD, OSHAUGHNESSY C, GANZ P (2005) Statin therapy, LDL cholesterol, C-reactive protein, and coronary artery disease. N Engl J Med 352: 29-38.

OLSON AL, SWIGRIS JJ, LEZOTTE DC, NORRIS JM, WILSON CG, BROWN KK (2007) Mortality from pulmonary fibrosis increased in the United States from 1992 to 2003. Am J Respir Crit Care Med 176: 277-284.

OU XM, FENG YL, WEN FQ, HUANG XY, XIAO J, WANG $\mathrm{K}$, WANG T (2008) Simvastatin attenuates bleomycin-induced pulmonary fibrosis in mice. Chin Med J (Engl) 121: 1821-1829.

PALMER G, CHOBAZ V, TALABOT-AYER D, TAYLOR S, SO A, GABAY C, BUSSO N (2004) Assessment of the efficacy of different statins in murine collagen-induced arthritis. Arthritis Rheum 50: 4051-4059.

PEREL P, ROBERTS I, SENA E, WHEBLE P, BRISCOE C, SANDERCOCK P, MACLEOD M, MIGNINI LE, JAYARAM P, KHAN KS (2007) Comparison of treatment effects between animal experiments and clinical trials: systematic review. BMJ 334: 197.

REAGAN-SHAW S, NIHAL M, AHMAD N (2008) Dose translation from animal to human studies revisited. FASEB J 22: 659-661.
RIDKER PM, RIFAI N, PFEFFER MA, SACKS FM, MOYE LA, GOLDMAN S, FLAKER GC, BRAUNWALD E (1998) Inflammation, pravastatin, and the risk of coronary events after myocardial infarction in patients with average cholesterol levels. Cholesterol and Recurrent Events (CARE) Investigators. Circulation 98: 839-844.

SCOTTON CJ, CHAMBERS RC (2007) Molecular targets in pulmonary fibrosis: the myofibroblast in focus. Chest 132: 1311-1321.

SERRANO-MOLLAR A, CLOSA D, CORTIJO J, MORCILLO EJ, PRATS N, GIRONELLA M, PANES J, ROSELLO-CATAFAU J, BULBENA O (2002) P-selectin upregulation in bleomycin induced lung injury in rats: effect of N-acetyl-L-cysteine. Thorax 57: 629-634.

VOLTZ JW, CARD JW, CAREY MA, DEGRAFF LM, FERGUSON CD, FLAKE GP, BONNER JC, KORACH KS, ZELDIN DC (2008) Male sex hormones exacerbate lung function impairment after bleomycin-induced pulmonary fibrosis. Am J Respir Cell Mol Biol 39: 45-52.

WATTS KL, SAMPSON EM, SCHULTZ GS, SPITERI MA (2005) Simvastatin inhibits growth factor expression and modulates profibrogenic marker in lung fibroblasts. Am J Respir Cell Mol Biol 32: 290-300.

WOCKEL W, SULTZ J (1995) Diffuse pulmonary fibrosis and HermanskyPudlak syndrome. Thorax 50: 591.

ZEKI AA, FRANZI L, LAST J, KENYON NJ (2009) Simvastatin inhibits airway hyperreactivity: implications for the mevalonate pathway and beyond. Am J Respir Crit Care Med 180: 731-740.

ZHU Z, HOMER RJ, WANG Z, CHEN Q, GEBA GP, WANG J, ZHANG Y, ELIAS JA (1999) Pulmonary expression of interleukin-13 cause inflammation, mucus hypersecretion, subepithelial fibrosis, physiologic abnormalities, and eotaxin production. J Clin Invest 103: 779-788. 